\title{
INCLUSÃO ESCOLAR E ENSINO DE ARTE: APROXIMAÇÕES
}

\section{Maria Flávia Silveira Barbosa}

Centro Universitário Adventista de São

Paulo

\section{Resumo:}

Este artigo pretende contribuir para as reflexões teóricas acerca do problema da orientação inclusiva no campo da Educação e as implicações - limites e possibilidades - dessa perspectiva para o ensino de arte nas escolas regulares. Partese da análise de documentos oficiais, buscando compreender termos como inclusão, diversidade, diferença, suas origens, seus fundamentos e seus usos na Educação Especial. Em seguida, afirmaseo direito à educação como questão fundamental subjacente aoproblema da inclusão escolar, tentando inserir a educação dos especiais, dos excluídos, dos diferentes no âmbito do direito humano à educação. $O$ texto se baseia ainda nas formulações de Georg Lukács e Lev Vigotskisobre arte e educação estética para defender a importância do ensino de arte na formação omnilateral de todos indivíduos.

Palavras-chave: Inclusão Escolar; Direito à Educação; Ensino de Arte. 


\title{
SCHOOL INCLUSION AND ART EDUCATION:
}

\section{APPROACHES}

\begin{abstract}
:
This article aims to contribute to the theoretical reflections on the problem of inclusive orientation in Education area and the implications - limits and possibilities -of this perspective to the teaching of art in mainstreams schools. It starts with an analysis of official documents, trying to understand terms such as inclusion, diversity, difference, its origins, its foundations and its uses in Special Education. Then states the right to education as a fundamental issue underlying the problem of school inclusion, trying to insert the education ofthe special, the excluded and the different in the human right to education. The text is alsobased on Georg Lukács and Lev Vygotsky's formulations about art and aesthetic education to advocate the importance of art education on integral human development.
\end{abstract}

Key words: School Inclusion; Right to Education; Teaching of Art. 


\section{Palavras iniciais}

O tema inclusão e seus múltiplos determinantes precisam ser ainda mais estudados no campo do ensino de arte. O texto que apresento aqui é uma pequena contribuição no sentido de ampliar as perspectivas de reflexão teórica sobre esse tema tão candente na Educação e acrescentar elementos ao debate.Proponho-me, então, a buscar os sentidos de alguns termos/conceitos, entre eles: educação especial, inclusão, exclusão, diferença, diversidade, desigualdade, baseando-me nas disposições de documentos oficiais, mas também nas reflexões de educadores com os quais partilho ideais e luta por uma educação emancipadora e democratizante. Tento encontrar respostas para algumas questões que considero primordiais: em quais contextos e por que esses termosaparecem no campo da Educação? A quem se referem? Quem são os especiais? Quem são os excluídos? Por que e como devem ser incluídos? Quem são os diferentes? O que revelam esses termos? O que ocultam?

A seguir, busco compreender aquela que considero a questão de fundo do problema: o direito à educação. A tentativa é entender o direito à educação dos especiais, dos excluídos, dos diferentes, no âmbito do direito de todos à educação. Acredito que a solução para ambos problemas - a inclusão e o direito à educação - passa pelos mesmos caminhos; se é que são dois problemas...

Faço, então, o esforço de trazer essas questões para o campo do ensino de arte e finalizo, defendendo a ideia de que esse problema é parte do problemamaior do acesso/direitoà artee seu ensino para todas as nossas crianças e jovens; e proponho, fundamentando-me em Lev S. Vigotski (1997; 1998; 2004; 2009) e GeorgLukács (KONDER, 1996; DUARTE, 2010; FERREIRA, 2013), um referencial teórico que considero promissor no sentido da valorização da arte na formação de todos os indivíduos.

Pode ser que outros educadores, profissionais da área de arte, considerem pouco frutífera a elaboração teórica sobre esse tema, preferindo as contribuições didático-metodológicas; o que considero indispensável, porém 
não suficiente. A intençãodeste texto é, por outro lado, afastar-me de soluções rápidas e pontuais, buscando a raiz de problemas que se colocam no dia-a-dia da prática educativa, em qualquer área. A intenção é evitar o abraço acrítico e incondicional a concepções que nos são apresentadas com caráter de inovação, nos são impostas como panaceia, mas que, ao fim e ao cabo, não ajudam a superar os enormes problemas educacionais que, ainda no século XXI, atormentam o nosso país.

\section{Em busca de um pouco de luz}

No prefácio do livro "Educação Especial e Teoria Histórico-Cultural" (BARROCO et al., 2012), Saviani (2012, p. 07) lembra, não sem um tom de crítica, o quanto são recorrentes no campo da Educação as mudanças de terminologia, "como se isso resolvesse os problemas enfrentados". Acrescento uma impressão pessoal: parece-me que tais mudanças acabam camuflando os problemas que, apresentados sob óticas renovadas, não são concretamente compreendidos e assumidos, quer por aqueles que propõem as mudanças quer pelos profissionais que atuam nas escolas. No que toca ao tema aqui estudado, diz Saviani que passamos de criança deficiente a criança excepcional e a criança portadora de necessidades especiais. Hoje, temos a educação inclusiva, cujo fundamento é o reconhecimento da diversidade e do direito à diferença ${ }^{1}$. Penso que o caminho a ser trilhado, neste texto, ajudará a elucidar esses termos.

Vejamos o que diz a Declaração de Salamanca (1994) acerca da inclusão. Esse documento - que causou forte impacto na Educação Especial no Brasil, refletindo-se em dispositivos legais como as Diretrizes Nacionais para a Educação Especial na Educação Básica (BRASIL, 2001) e a Política Nacional para a Educação Especial na Perspectiva da Educação Inclusiva (BRASIL, 2011) - propõe o acesso à escola regular às crianças com

\footnotetext{
${ }^{1}$ Para esclarecimento acerca da concepção de subjetividade que respalda a ideia de educação inclusiva, cf. NAGEL, L.H. Coletividade e subjetividade na sociedade contemporânea: questões educacionais que afetam a educação especial. In: BARROCO, S. M. S.; LEONARDO, N. S. T.; SILVA, T. dos S. A. da (orgs.). Educação especial e teoria histórico-cultural: em defesa da humanização do homem. Maringá: EDUEM, 2012.

Olh@res, Guarulhos, v. 3, n. 1, p. 143-167. Maio, 2015.
} 
necessidades educativas especiais. As escolas devem, a partir de então, se adaptar às crianças e não as crianças à escola, chamando-se a essa perspectiva "pedagogia centrada na criança"; uma pedagogia que seria capaz de "ir ao encontro" das necessidades de cada criança. É esse o princípio da educação inclusiva. Não se explicita detalhadamente a pedagogia centrada na criança, mas o foco do discurso é no aprender: todas devem ter oportunidade de aprender segundo seus ritmos e interesses próprios $^{2}$. Em que pese a importância fundamental dessa proposição, penso que a forte ênfase no aprender deixa um tanto vago o lugar do ensino, a começar pelo papel do professor, nesse contexto.Qual a natureza do aprendizadoa que se está referindo, então? Se pensarmos em uma classe de escola pública no Brasil, com 35 a 45 alunos em uma boa hipótese - cada um com seus interesses e ritmos diferentes -, como deverá trabalhar o professor? Temo que, em situações como essa, as aprendizagens acabem ficando só no campo da socialização e da informalidade, sendo considerada de menor importância a aquisição de conhecimentos sistematizados; o que, segundo as concepções que assumo, é a especificidade da educação escolar.

Em nosso país, as Diretrizes Nacionais para a Educação Especial na Educação Básica (BRASIL, 2001) fazem eco à ideia de que as crianças com necessidades educacionais especiais devem estar nas escolas regulares, conforme se lê no art. $2^{\text {o: }}$ "os sistemas de ensino devem matricular todos os alunos, cabendo às escolas organizar-se para o atendimento aos educandos com necessidades educacionais especiais, assegurando as condições necessárias para uma educação de qualidade para todos" (BRASIL, 2001, p. 01). Marca ainda o início do atendimento a essas crianças para o nível da Educação Infantil. De acordo com as Diretrizes, a Educação Especial é uma modalidade da Educação Básica à qual cabe assegurar recursos (humanos, materiais e financeiros) e serviços educacionais especiais "para apoiar, complementar, suplementar e, em alguns casos, substituir os serviços educacionais comuns" (BRASIL, 2001, p. 01). Fica claro que o atendimento

\footnotetext{
${ }^{2}$ No documento, afirma-se reiteradamente que a perspectiva da escola inclusiva já alcançou sucesso em vários países, mas não há uma indicação clara de quais sejam esses países e nem de quais foram as condições (sociais, econômicas, pedagógicas) que possibilitaram o sucesso.

Olh@res, Guarulhos, v. 3, n. 1, p. 143-167. Maio, 2015.
} 
aos educandos com necessidades especiais deve ser feito em classes comuns do ensino regular, sendo considerado o recurso às classes especiais de caráter transitório.

Outra ideia que está em consonância com a Declaração de Salamanca é a de que as escolas devem se adaptar às crianças. A adaptação, contudo, não parece ser um caminho promissor já que muitas vezes se reflete na ideia de redução ou minimização do currículo e concomitante ampliação do tempo escolar para as crianças com necessidades educacionais especiais. Senão, vejamos.

Art. $8^{\circ}$ As escolas da rede regular de ensino devem prever e prover na organização de suas classes comuns:

$[\ldots]$

III - flexibilizações e adaptações curriculares que considerem o significado prático e instrumental dos conteúdos básicos, metodologias de ensino e recursos didáticos diferenciados e processos de avaliação adequados ao desenvolvimento dos alunos que apresentam necessidades educacionais especiais, em consonância com o projeto pedagógico da escola, respeitada a frequência obrigatória;

$[\ldots]$

VIII - temporalidade flexível do ano letivo, para atender às necessidades educacionais especiais de alunos com deficiência mental ou com graves deficiências múltiplas, de modo que possam concluir em tempo maior o currículo previsto para a série/etapa escolar, principalmente nos anos finais do Ensino Fundamental, conforme estabelecido por normas do sistema de ensino, procurando-se evitar grande defasagem idade/série (BRASIL, 2001, p. 03).

Os currículos devem, portanto, se ajustar às condições dos alunos (conforme o art. $10^{\circ} \S 2^{\circ}$ ). Penso que essa é uma premissa pedagógica que precisa ser analisada com cuidado. Se é verdade que os currículos escolares devem ser flexíveis, também é verdade que tal flexibilidade não pode chegar a resumir os conteúdos escolares àquilo que tenha "significado prático e instrumental". Parece-me que as condições do educando são vistas como um dado natural para cuja transformação o currículo (conteúdos, metodologias etc.) pouco ou nada pode contribuir. $\mathrm{O}$ currículo escolar não é visto como 
fator de desenvolvimento para o aluno com necessidades educacionais especiais. Estamos, pois, diante de uma concepção naturalizante do desenvolvimento humano e a ela se deveopor uma concepção que considere o homem como ser social e histórico. Alexis N. Leontiev, um dos principais formuladores da Psicologia Histórico-Cultural, esclarece:

[...] o desenvolvimento mental da criança é qualitativamente diferente do desenvolvimento ontogénico do comportamento nos animais. Esta diferença provém, sobretudo, da ausência nos animais, de um processo essencial no desenvolvimento da criança: o processo de apropriação da experiência acumulada ao longo da história social. // Desde o nascimento, a criança é rodeada por um mundo objectivo criado pelos homens; são os objectos correntes, as roupas, os instrumentos mais simples, a língua e as concepções, as noções, as ideias que o reflectem. Os próprios fenômenos naturais encontra-os a criança nas condições criadas pelos homens: as roupas protegem-na do frio, a iluminação artificial afasta as trevas danoite. Pode-se dizer que a criança começa seu desenvolvimento psíquico num mundo humano $^{3}$ (LEONTIEV, 1978, p. 319-320 - grifo do autor).

Assim, ao invés de postular uma adaptação que restrinja o currículo escolar às condições - entendidas como um dado natural e imutável - da criança com necessidades especiais, deve-se pensar, ao contrário, em um currículo escolar talvez ainda mais rico e pleno de conteúdos científicos, filosóficos e artísticos do que o destinado às outras crianças; um currículo que promova o seu desenvolvimento à altura das máximas possibilidades disponíveis para o gênero humano. A adaptação, a meu ver, deve priorizar, não a redução do currículo e a ampliação do tempo escolar, mas a criação de meios para que a criança com necessidades especiais se desenvolva plenamente. Em passagem de seu livro "Fundamentos de Defectologia", Lev S. Vigotski (1997) afirma que não devemos nos conformar que a escola especial pratique um currículo reduzido e metodologias facilitadas e simplificadas, em comparação com a escola regular; segundo o autor, é preciso encontrar

\footnotetext{
${ }^{3}$ Grafia original.

Olh@res, Guarulhos, v. 3, n. 1, p. 143-167. Maio, 2015.
} 
formas positivas, formas especiais de trabalhar que respondam às peculiaridades da criança deficiente ${ }^{4}$.

Em seu livro "O desenvolvimento do psiquismo e a educação escolar: contribuições à luz da psicologia histórico-cultural e da pedagogia históricocrítica", Martins (2013) afirma justamente o protagonismo da educação escolar - cuja função é a transmissão do saber sistematizado - no desenvolvimento psíquico da criança. Diz a autora:

[...] se é fato que a educação escolar promove desenvolvimento, também é fato que o desenvolvimento não resulta de qualquer modelo de educação escolar. Conforme procuramos demonstrar, o ensino que se volta aos objetivos desenvolvimentistas não é aquele que reproduz na escola a cotidianidade, marcada pela heterogeneidade, pelo espontaneísmo, por ações assistemáticas; também não é aquele que esvazia a educação escolar dos conteúdos clássicos, dos conteúdos científicos em nome dos conteúdos do senso comum, de conceitos espontâneos e de pseudoconceitos, operando nos limites do pensamento empírico. Igualmente, não é aquele que atribui as possibilidades da aprendizagem às particularidades individuais dos alunos, presentes em seu desenvolvimento real, mantendo-os reféns do que são em detrimento daquilo que podem vir a ser (MARTINS, 2013, p. 307 - grifos meus).

Penso ser correto, então, afirmar que é preciso bastante cautela com os sentidos da adaptação postulada em certos documentos oficiais; no caso das Diretrizes, mormente no que se refere à priorização de conteúdos básicos com "significado prático e instrumental" . Assumir como premissa que o desenvolvimento de uma criança ou jovem está irremediavelmente definido no nível "prático e instrumental" é negar a eles inúmeras possibilidades de "vir a ser".

Voltemos à Declaração de Salamanca. Seus signatários (quase cem países e vinte e cinco organizações internacionais) reafirmam o direito de todos à educação, preconizado pela Declaração Universal dos Direitos Humanos

\footnotetext{
${ }^{4}$ Ao tempo de Vigotski e seus colaboradores - início do século XX -, a Defectologia era o nome da área de conhecimento a qual hoje chamamos Educação Especial. Trata das questões da deficiência, mas acredito que suas reflexões se apliquem também ao termo atual "necessidades educativas especiais". E embora se referindo distintamente à escola regular e à escola especial, penso que o inconformismo em relação a esse tipo de adaptação deve ser ainda maior se for praticada dentro da mesma instituição; instituição que supostamente deveria "incluir".

${ }^{5}$ Adiante, tratarei das implicações dessa disposição para o ensino de arte.

Olh@res, Guarulhos, v. 3, n. 1, p. 143-167. Maio, 2015.
} 
(DUDH), de 1948. Considero lamentável que seja necessário ratificar a DUDH quase 60 anos depois; principalmente no que toca ao direito à educação, que segundo Gentili (2009, p. 1074) é um direito "que constrói e amplia outros direitos". A DUDH estabeleceu a educação como direito humano, em outras palavras, um direito de todos os homens; não deveria ser preciso incluir a posteriori aqueles com necessidades educativas especiais. Isso, entretanto, não parece ser consenso, de modo que a Declaração de Salamanca delimita sua abrangência afirmando:

[...] as escolas se devem ajustar a todas as crianças, independentemente das suas condições físicas, sociais, linguísticas ou outras. Neste conceito, terão de incluir-se crianças com deficiência ou sobredotados, crianças da rua ou crianças que trabalham, crianças de populações remotas ou nómadas, crianças de minorias linguísticas, étnicas ou culturais e crianças de áreas ou grupos desfavorecidos ou marginais. Estas condições colocam uma série de diferentes desafios aos sistemas escolares. No contexto deste Enquadramento da Acção, a expressão "necessidades educativas especiais" referese a todas as crianças e jovens cujas carências se relacionam com deficiências ou dificuldades escolares. Muitas crianças apresentam dificuldades escolares e, consequentemente, têm necessidades educativas especiais, em determinado momento da sua escolaridade. As escolas terão de encontrar formas de educar com sucesso estas crianças, incluindo aquelas que apresentam incapacidades $\operatorname{graves}^{6}(1994$, p. $06-$ grifos do documento).

Vê-se pelo trecho acima como o documento se equivoca na tentativa de assumir uma postura não preconceituosa, não discriminatória ante as diferenças. Ora, são muito diferentes as diferenças ali colocadas. Diferenças ou necessidades especiais advindas de graves problemas sociais e de problemas biofísicos (mais ou menos graves) são tratados da mesma forma; com a agravante de destinar a escola como panaceia para todos eles. São de naturezas muito diferentes os problemas em si e também as especificidades (sociais, econômicas, pedagógicas, médicas) requeridas para o desenvolvimento educacional de crianças gravemente incapacitadas ou

\footnotetext{
${ }^{6}$ Grafia original.

Olh@res, Guarulhos, v. 3, n. 1, p. 143-167. Maio, 2015.
} 
pertencentes a grupos minoritários; ou de meninos de rua ou crianças trabalhadoras; ou de crianças consideradas "superdotadas" ou daquelas que apresentam dificuldades no aprendizado etc. As afirmações anteriores parecem veicular uma concepção não-crítica das relações entre educação e sociedade, nos termos de Saviani (2002, p. 03-34). A escola é elevada à categoria de redentora da humanidade, como se o direito à educação, seja aquele preconizado pela DUDH, seja o tratado na Declaração de Salamanca, pudesse ser garantido apenas no âmbito dessa instituição ${ }^{7}$.

Estarei preconizando, em pleno século XXI, que as crianças especiais, diferentes, excluídas sejam colocadas em hospitais, sanatórios ou asilos, que sejam separadas das outras crianças? Não, evidentemente. A ideia que defendo é a seguinte: se as necessidades são especiais, então, é preciso meios especiais para garantir o atendimento a elas.Defendo, portanto,não o direito à diferença, à diversidade, mas o direito à igualdade. Direito de ter direitos iguais (e, naturalmente, também deveres e compromissos iguais). Mas essa igualdade a que me refiro só pode ser efetiva no ponto de chegada; penso que, muitas vezes, o discurso do direito à diferença se revela como uma tentativa de colocar a igualdade no ponto de partida. Mas se uma criança é cega em uma sociedade visual como a nossa; se uma criança fala outro idioma em casa que não a língua ensinada na escola; se uma criança tem que trabalhar antes de ir à escola; se uma criança é vítima de violência doméstica; se uma criança é filha de pais analfabetos, então, o seu ponto de partida não é o mesmo em relação às outras crianças que não vivenciam essas condições. A aceitaçãodessas condiçõescomo iguais no ponto de partida - o que me parece ser a face oculta do discurso do respeito às diferenças - se caracteriza, a meu ver, como aceitação das profundas injustiças e desigualdades promovidas pela sociedade capitalista, como se configura na atualidade. Penso que a garantia de direitos iguais para indivíduos diferentes requer meios diferentes.

\footnotetext{
${ }^{7}$ É bem verdade que na Declaração de Salamanca são propostas diretrizes para outras instâncias da sociedade, mas é forçoso reconhecer que o peso da responsabilidade cai mais sobre a escola e seus profissionais. Olh@res, Guarulhos, v. 3, n. 1, p. 143-167. Maio, 2015.
} 
Em seu texto "Quando o discurso da diferença desdenha a desigualdade: as armadilhas da inclusão”, Klein e Silva (2012, p. 32-33) dizem:

[...] em termos gerais, as diferenças individuais precisam ser consideradas no processo pedagógico. Porém, o trato que se dará às diferenças - ignorá-las, respeitá-las, superá-las, combatê-las -, dependerá da natureza dessas diferenças. E, aqui, é fundamental estabelecer o contraponto entre diferença e desigualdade. [...] Há diferenças que não resultam em nenhuma limitação para os sujeitos nem interferem no seu desenvolvimento ou na sua inclusão social. Estas podem e, via de regra, são ignoradas. Entretanto, quando essas diferenças são impeditivas da plena realização do sujeito, por certo devem ser superadas ou, até mesmo, se for o caso, combatidas - o que não quer dizer, esclareça-se enfaticamente, combater o sujeito, mas combater aquilo que constitui uma causa de limitação para ele.

As autoras apresentam como exemplo de diferença que precisou ser superada ao longo da história humana as limitações às quais os cegos foram sujeitos, durante muitos séculos, até a criação e divulgação da escrita Braille, quando puderam, finalmente, ser "incluídos" no mundo letrado. Da mesma forma, apontam a exibição de legendas em filmes e programas de televisão, no Brasil, como um avanço na possibilidade de acesso à cultura para os surdos. Por outro lado, afirmam que há "diferenças que devem ser vigorosamente combatidas: são aquelas resultantes das desigualdades sociais, o que equivale a dizer que se deve combater essas desigualdades" (KLEIN\& SILVA, 2012, p. 33).

Ora, não há possibilidade de combater as desigualdades sociais longe da luta pela transformação social, pois, como afirma Sader (2001, p. 76 - grifos meus),

[...] nunca a humanidade contou com tantos recursos tecnológicos para propiciar condições básicas de vida para o conjunto da população mundial. O ritmo de crescimento da população ao longo do século $[\mathrm{XX}]$ foi grande, mas tendeu a diminuir nas décadas finais. No entanto, ao aumento da capacidade de produzir não correspondeu um direcionamento

Olh@res, Guarulhos, v. 3, n. 1, p. 143-167. Maio, 2015. 


\begin{abstract}
dessa produção para os bens que a humanidade requer, dado que é o mercado universo muito restrito, definido por quem tem recursos para comprar - que determina o que se produz. Os problemas se situam em outro plano - o da distribuição. [...] Se trata de uma distribuição cada vez mais concentrada dos recursos nas mãos de alguns países e, dentro desses países, dos setores que já contam com um nível de vida incomparavelmente superior ao dos demais. Trata-se, portanto, de um problema social, de forma de organização econômico-social, que impede que os bens, produzidos em cada vez maior quantidade pelos homens, sejam apropriados pela maioria - de países e de setores sociais.
\end{abstract}

Sendo assim, parece ilusório falar em inclusão escolar sem considerar que esse processo é parte de um problema maior - a exclusão social; ou dito de outra forma, sem considerar que inclusão e exclusão são as duas faces da mesma moeda. Um mergulho minucioso na obra de Karl Marx permitiu a Oliveira (2004) desvelara exclusão como parte da lógica capitalista. De acordo com o autor, o círculo entre exclusão e inclusão "é condição de possibilidade dos processos de produção e reprodução do capital" (OLIVEIRA, 2004, p. 23-24). Não há espaço, neste texto, para reapresentar todo o percurso dos estudos de Oliveira;apenas tomarei de empréstimo suas reflexões, resumidamente. De acordo com o filósofo brasileiro, o termo exclusão aparece já nos primeiros escritos de Marx, mas em "O Capital”, ao analisar a mercadoria como a célula da sociedade capitalista e buscando sua gênese, revela-se que "o homem - sujeito produtor da mercadoria - é excluído de sua rede lógica [da produção da mercadoria], enquanto ser complexo, de múltiplas determinações, e reincluídocomo ser unilateralmente determinado, depois de ser irremediavelmente reduzido à condição de simples quantum econômico" (OLIVEIRA, 2004, p. 126 grifos do autor); esse é um processo de deformação ou redução ontológica, conforme diz o autor. Como isso acontece, a princípio?

Em poucas palavras, com a apropriação privada dos bens de produção (que ocorre na Europa, nos séculos XVII e XVIII), os camponeses são expulsos do campo e migram, inevitavelmente, para as cidades, onde sólhes resta vender sua força de trabalho, aceitando quaisquer condições impostas pelos novos senhores - os capitalistas -, em troca de um salário. Nessa relação organicamente desigual, aos trabalhadores, apenas o necessário para a 
reprodução da sua própria força de trabalho; e aos proprietários, a acumulação de mais e mais riquezas. É nesse sentido que o homem (o trabalhador, o operário) é, primeiramente, expropriado, expulso, alienado do processo produtivo; para ser, depois, recolocado, ou incluído, em uma nova lógica - a lógica do capital. Ele, contudo, é incluído em condições de extrema precariedade, em condições extremamente desiguais; e, de totalidade síntese de múltiplas determinações, esse homem se torna apenas força de trabalho - categoria exclusivamente quantitativa, diz Oliveira (2004). Como se vê, não é possível pensarna superação da exclusão como a inclusão das pessoas excluídas no modelo capitalista de sociedade - esse é um modelo necessariamente excludente. A superação da exclusão virá somente com a superação do modo de produção capitalista - fundado sobre interesses particulares de classe -, em favor de uma nova sociedade, sem classes - fundada sobre interesses universais(PADILHA\& BARBOSA, 2013).

Até aqui, tentei compreender alguns termos como inclusão, exclusão, diferença, diversidade e seu uso no âmbito da Educação e da Educação Especial. Ao analisar documentos oficiais, de âmbito multilateral e nacional, levantei alguns pontos, na tentativa de estimular o debate. Muitas outras reflexões seriam pertinentes em relação a esses termos, que se referem a problemas sociais e educacionais graves. Muitos outros pontos poderiam ser levantados; mas não seria possível tratar de todos eles, nesse momento. Sigo, agora, rumo ao que considero a questão fundamental: o direito de todos à educação.

\section{Questão de fundo: o direito à educação}

Um problema é sempre parte de um todo; está interligado a outros problemas. E a busca por soluções passa por uma "visão de conjunto"; só a visão de conjunto dá a dimensão de cada elemento do problema (KONDER, 1984). Mesmo sendo provisória - porque o mundo está sempre em transformação e também as relações entre os homens, os diversos aspectos Olh@res, Guarulhos, v. 3, n. 1, p. 143-167. Maio, 2015. 
da vida social etc. - e a realidade mais rica do que o conhecimento que se pode ter dela, é necessário o esforço para alcançar a visão de conjunto; para alcançar a síntese. Diz Konder (1984, p. 37 - grifo do autor): “a síntese é a visão de conjunto que permite ao homem descobrir a estrutura significativa da realidade com que se defronta numa situação dada. E é a essa estrutura significativa - que a visão de conjunto proporciona - que é chamada de totalidade". É preciso tomar cuidado, entretanto, porque a totalidade não é o resultado da soma das partes de um problema, mas uma estrutura complexa cuja compreensão requer a mediação da análise.Dependendo do nosso esforço, podemos alcançar diferentes níveis de totalidade.

Farei agora uma tentativa em relação ao tema estudado, buscando compreender a questão da educação inclusiva no âmbito maior do direito de todos à educação. Penso que só é preciso falar em educação inclusiva porque esse direito nãoestá garantido a todos os indivíduos. Gentili(2009) apresenta uma reflexão que ajuda a desvelar as razões, como e porqueesse direito não está garantido, descrevendo três dinâmicas que, na América Latina e no Caribe, funcionam como barreiras à sua plena realização. São essas dinâmicas: a pobreza e a desigualdade estruturais, a diferenciação dos sistemas nacionais de educação e os sentidos do direito à educação na sociedade capitalista.

Segundo o autor, as condições de extrema pobreza, de desigualdade e de injustiça que marcam o processo de desenvolvimento na América Latina são fatores que impedem que o acesso à escola - oportunizado pela expansão das redes de ensino público - se configure efetivamente como a democratização do direito à educação; tais condições atingem de modo mais perverso a população em idade escolar. Diz Gentili (2009, p. 1065-1066):

[...] desde a primeira infância até a adolescência, as condições de pobreza e indigência interferem de maneira intensa nas oportunidades educacionais dos mais pobres. O ciclo que vai do nascimento ao prematuro ingresso no mercado de trabalho, também acompanhado, no caso das meninas, pelo exercício prematuro de uma maternidade marcada por riscos e por uma assistência médica precária, 
condiciona seriamente as oportunidades educacionais da infância latino-americana e caribenha, questionando seu direito à própria vida.

À pobreza se associa a desigualdade social que produz também reflexos na educação. Assim, o panorama que se apresenta é: todos têm direito à educação, mas as escolas estão diferenciadas em escolas pobres para alunos pobres e escolas ricas para alunos ricos. Nessas escolas, são diferentes o acesso aos recursos (físicos, econômicos, didáticos, humanos etc.), o perfil dos docentes e dos alunos que nelas transitam, o tipo e a qualidade dos conhecimentos ministrados. Dessa forma, complexifica-sea questão da exclusão versuso direito à educação, caracterizando um processo chamado por Gentili de exclusão includente - processo através do qual a exclusão educacional ganha novas feições, "no contexto de dinâmicas de inclusão e inserção institucional" (2009, p. 1061). Tais dinâmicas acabam se revelando infrutíferas por tentar abordar o problema da exclusão de maneira pontual, sem considerar seu caráter multiplamente determinado.

Gentili (2009, p. 1072) lembra ainda a perspectiva humanista assumida pela Declaração Universal dos Direitos Humanos (DUDH), em relação ao direito à educação. Segundo ele,

[...] a Declaração de 1948 reconhecerá que a educação é um direito humano, um bem público e social, porque ela nos ajuda a nos comportarmos e a nos reconhecermos como seres humanos livres e iguais em direitos, a nos tratarmos de maneira fraternal, a lutar contra toda forma de escravidão e servidão, contra toda forma de discriminação, tortura e tormento, de aspiração colonial ou imperial; a educação protege-nos e é a defesa de nossa identidade, de nossa privacidade e de nossa honra, de nossa liberdade e da liberdade de todos, da dignidade, da felicidade (ela mesma, um bem comum), de toda liberdade de pensamento, do bem-estar, do acesso à riqueza acumulada, à saúde, à vivência plena de nossa sexualidade, nossa cultura e nossa moralidade. 
Entretanto, na sociedade sob a égide do capital, sobretudo, a partir de meados da década de 1940 até os nossos dias, a educação assume importância pelos efeitos que supostamente pode causar no desenvolvimento econômico de um país. Estabelece-se, pois, sob essa perspectiva, uma relação linear e inequívoca entre educação e desenvolvimento econômico; a educação entra na lógica do mercado e argumentos como produtividade, competitividade, empregabilidade, aumento de riqueza (nacional e pessoal), entre outros, tornam-se muito presentes nos discursos sobre a educação. Ficam esquecidos os valores éticos e humanistas que fundamentaram o direito humano à educação na DUDH.Para o autor, lutar pelo sentido do direito à educação, como preconizado na DUDH, insere-se na luta maior por uma sociedade mais justa e igualitária; diz ele: "o futuro do direito à educação e a luta contra a exclusão refletem-se no mesmo horizonte" (GENTILI, 2009, p. 1075).

Espero ter conseguido demonstrar, com a ajuda de Gentili, o quanto a questão da inclusão escolar de crianças com necessidades educativas especiais está ligada à questão do direito humano à educação e o quanto os problemas que elas encerram não serão superados fora de um movimento radical de transformação da sociedade. Não se pode esquecer, entretanto, que a própria educação tem um papel importante a desempenhar nesse movimento. Como dizem Padilha e Oliveira (2013, p. 189),

[...] o papel da educação se torna essencial para a automudança consciente e para a concretização de outra ordem social. É importante ter claro que a sociedade não é uma abstração; a vida individual e a vida coletiva são faces de uma totalidade, e a transformação de uma dessas faces implica necessariamente mudanças na outra.

\section{Ensino de arte e inclusão escolar}

Falta agora refletir sobre o lugar do ensino de arte nessa problemática. Quais as aproximações possíveis entre ensino de arte e inclusão escolar? Teria a arte um papel diferenciado na educação das crianças com necessidades 
especiais? Qual abordagem teórico-metodológica seria mais promissora para o trabalho junto a essas crianças? Há espaço para esse trabalho nas escolas regulares? Seguindo a diretriz anterior que recomenda buscar umavisão de conjunto do problema, penso não ser falso afirmar que, assim como a inclusão escolar é parte de um problema mais amplo - a exclusão social cuja superação requer a garantia do direito à educação para todos os indivíduos, também a questão do ensino de arte, sua presença ou ausência na formação daqueles com necessidades educativas especiais, insere-se no âmbito do problema maior que é a garantia de uma educação estéticasignificativa para todas as nossas crianças e jovens.

Assim, considero pertinente iniciar a reflexão justamente buscando um referencial teórico que afirme o valor da arte na formação humana. Nesse sentido, encontroos subsídios necessáriosna teoria histórico-cultural, sobretudo nos estudos de Lev S. Vigotski $(1997 ; 1998 ; 2004 ; 2009)$ acerca da arte e da educação estética, e nas concepções sobre estética do filósofo húngaro Georg Lukács (KONDER, 1996; DUARTE, 2010; FEREIRA, 2013). Vejamos o que dizem os autores.

Tanto Vigotski como Lukács se fundamentam no materialismo histórico e dialético de Karl Marx, em seus estudos. E para Marx, todos os sentidos humanos, os artísticos inclusive, são cultivados e criados a partir da apropriação das objetivações - do campo da arte, da ciência, da técnica, da filosofia etc. - elaboradas pela humanidade, ao longo dos tempos. Diz ele,

[...] é somente graças à riqueza objetivamente desenvolvida da essência humana que a riqueza da sensibilidade humana subjetiva é em parte cultivada, e é em parte criada, que o ouvido torna-se musical, que o olho percebe a beleza da forma, em resumo, que os sentidos tornam-se capazes de gozo humano, tornam-se sentidos que se confirmam como forças essenciais humanas. Pois não só os cinco sentidos, como também os chamados sentidos espirituais, os sentidos práticos (vontade, amor, etc.), em uma palavra, o sentido humano, a humanidade dos sentidos, constituem-se unicamente mediante o modo de existência de seu objeto, mediante a natureza humanizada. A formação dos cinco sentidos é um trabalho de toda a história universal até nossos dias (MARX, 1974, p. 18 grifos do autor).

Olh@res, Guarulhos, v. 3, n. 1, p. 143-167. Maio, 2015. 
Asreflexões marxianas permitem a Vigotski e a Lukácsentender a arte - sua criação e fruição - como obra humana; quer dizer, não como algo advindo de uma inspiração, seja ela sobrenatural ou originária de processos internos, inatos e únicos, mas como resultado das relações concretas que os homens estabelecem na vida em sociedade. Sendo históricas essas relações, são históricas também as possibilidades de criação - as regras, normas e convenções para as elaborações artísticas e também as que estabelecem os critérios delimitadores daquilo que é ou não arte, em cada tempo, lugar etc. - e fruição artística - o acesso a museus, concertos, apresentações teatrais, literatura, a qualidade da arte a que se tem mais acesso, a possibilidade de ela estar ou não na escola etc. E são essas possibilidades (ou a ausência delas) que permitirão o desenvolvimento (ou não) das potencialidades artísticas para todos os indivíduos ou apenas para algunspoucos escolhidos.

Vigotski concebe a arte como técnica social do sentimento. Para ele, a arte toma da vida o seu material e o transforma em algo diferente, que não está, de modo óbvio, nele. Nesse processo, torna objetivos os sentimentos e permite aos homens com eles se relacionarem objetivamente, quer dizer, como se fossem objetos; nesse processo, chamado catarse ${ }^{8}$, os homens transformam seus próprios sentimentos, elaborando-os, superando-os. Essas concepções colocamVigotski em oposição a pensadores, seus contemporâneos, que postulavam a arte como contágio. Para esses pensadores, a função da obra de arte é transmitir para o fruidor os sentimentos expressos pelo autor. Assim, o sentimento individual do artista seria assimilado passivamente pelo apreciador da obra de arte, em um processo igualmente único e particular. $\mathrm{O}$ autor russo, ao contrário, mostra como essa relação é social desde o princípio: porque o artista, apesar de criar algo novo, toma sempre da vida social a matéria-prima para a sua criação. Portanto, o sentido do binômio criação-fruição é do social para o individual e não do individual para o social, como queriam os adeptos da teoria do contágio. Nesse processo, os indivíduos transformam seus próprios

\footnotetext{
${ }^{8}$ Vigotski toma de empréstimoesse termo a Aristóteles, que o usou primeiramente no campo da arte. Olh@res, Guarulhos, v. 3, n. 1, p. 143-167. Maio, 2015.
} 
sentimentos ao se apropriarem dos sentimentos objetivados pelo artista na obra de arte (VIGOTSKI, 1998; 2004).

De acordo com o filósofo húngaro Georg Lukács - que como Vigotski também assume dialeticamente a categoria aristotélica de catarse -, a arte é uma forma de conhecimento da realidade cuja especificidade é seu caráter sensível. Como forma de conhecimento da realidade, sua função é elevar o homem "a um estágio de plena consciência” (FERREIRA, 2013, p. 202); isso quer dizer que, na fruição da obra de arte, o indivíduo tem ricas possibilidades de superar e de se libertar das relações cotidianas, heterogêneas, alienadase alienantes de sua vida, transformando-se no que Lukács chama de "homem inteiramente". Konder (1996, p. 31) assim descreve o processo de transformação - catarse - que se dá nos indivíduos quando se apropriam significativamente das elaborações humanas no campo da arte: "na medida em que vai conseguindo concentrar suas energias criadoras em direções determinantes, passaa 'homogeneizar' suas atividades produtivas e cognitivas". O "homem inteiramente" é, portanto, homogeneizado, renovado, enriquecido, plenamente consciente. Como afirma Duarte (2010, p. 152), esse processo não acontece de maneira simples, direta e inequívoca:

[...] a catarse opera uma mudança momentânea na relação entre a consciência individual e o mundo, fazendo com que o indivíduo veja o mundo de maneira diferente daquela própria ao pragmatismo e ao imediatismo da vida cotidiana. Por meio dessa momentânea suspensão da vida cotidiana, a arte exerce efeito formativo sobre o indivíduo, efeito esse que terá repercussões na vida do indivíduo, as quais, porém, não ocorrem de maneira direta e imediata, havendo entre elas e a catarse estética uma complexa trama de mediações que torna impossível definir a priori as consequências para a vida de determinado indivíduo, do processo de recepção de determinada obra de arte.

Creio que essa breve apresentação das concepções de Vigotski e de Lukács acerca da importância, do papel da arte na vida do homem seja suficiente 
para prosseguir com a reflexão a que me proponho, neste trabalho. Cabe, então,perguntar: a que tipo de abordagem didático-metodológica levam essas concepções? A meu ver, o modo como Vigotski e Lukács compreendem a natureza da obra de arte e a sua função no desenvolvimento da consciência humana encaminham para uma prática pedagógica radicalmente diferentedos fazeres mais comuns que se pode observar no ensino de arte nas escolas regulares, seja esse ensino destinado a crianças com necessidades especiais ou não. São alguns desses fazeres:

1. O uso instrumental das linguagens artísticas - quando a música, as artes visuais, o teatro, a dança servem apenas como ferramenta para aprendizagens em outras áreas de estudo. O problema com esse tipo de abordagem é que os conteúdos próprios das linguagens artísticas ficam relegados a segundo plano, se é que chegam a ser trabalhados. Lembrando com Lukács que a arte é uma forma de conhecimento da realidade, cuja especificidade é seu caráter estético, sensível, é possível afirmar a importância de se tratar nas aulas de artedos conteúdos artísticos, dando a esse conhecimento um lugar concreto e autônomo na formação do indivíduo; a língua materna, a matemática, a biologia etc. já gozam desse privilégio, há anos;

2. Seu uso como entretenimento - penso que essa função de mero entretenimento que a arte assume na sociedade capitalista, sobretudo em sua configuração atual, serve apenas para obscurecer as possibilidades de ampliação da consciência que essa área de conhecimento poderia oferecer aos indivíduos (basta uma análise um pouco mais aprofundada das "obras de arte" mais veiculadas pelas mídias, para comprovar essa hipótese). A escola tem abraçado essa perspectiva,reiteradamente, negando à arte o seu valor para a compreensão da condição humana, do passado e do presente. Os autores aqui chamados contribuem para alterar esse panorama, já que a arte é vista como instrumento de catarse, quer dizer, de elaboração, 
reelaboração, superação de sentimentos ${ }^{9}$. As práticas fundamentadas nesse princípio são muito diferentes de preparar apresentações para ocasiões festivas, como se vê nas escolas;

3. Seu uso como forma de liberação de sentimentos e emoções - bastante presente no ideário dos profissionais da área e, também, em documentos oficiais $^{10}$, a concepção romântica de arte como comunicação e expressão tem sido, ao longo dos tempos, um dos maiores entraves à democratização do acesso à arte, por trazer subjacente as ideias de dom e talento inato. Essa concepção entende a arte como algo que aflora espontaneamente do indivíduo, cabendo ao educador não interferir em sua criatividade natural; nesse sentido, não haveria conteúdosespecíficos das linguagens artísticas a serem trabalhados - como defendi anteriormente -, mas cada criança ou jovem expressaria seus sentimentos e emoções, livremente. Com Vigotski, por outro lado, é possível compreender o movimento da criação artística como algo que vai do social para o individual e não contrário; assim, não há sentimentos ou emoções a serem libertos pela criação artística antes da apropriação pelo indivíduo das elaborações humanas no campo da arte. O autor russo afirma ainda o ensino de arte na escola como o caminho para o desenvolvimento da imaginação e da criação (VIGOTSKI, 2009).

Em contraposição a esses fazeres, as concepções de Vigotski e Lukács direcionam, a meu ver, para uma educação estética significativa, para crianças e jovens com e sem necessidades especiais. Mas vejamos o que acrescentam essas concepções para pensar as relações entre ensino de arte e inclusão escolar, voltando às disposições das Diretrizes Nacionais para a Educação Especial na Educação Básica (BRASIL, 2001) acerca da flexibilização e adaptação curricular. No art. $8^{\circ}$, inciso III - como se viu anteriormente - é recomendada a adaptação curricular no sentido, entre outros, de considerar o "significado prático e instrumental dos conteúdos

\footnotetext{
${ }^{9}$ Fica claro, penso eu, que não é qualquer criação no campo da arte, que carrega o potencial catártico para os autores. Não há como negar que as mídias têm veiculado muito mais criações artísticas alienantes do que aquelas que poderiam ampliar as consciências.

${ }^{10}$ Por exemplo, os Parâmetros Curriculares Nacionais-Arte (BRASIL, 1997; 1998) e o Referencial Curricular Nacional para a Educação Infantil, em seu volume 3: Conhecimento de Mundo/ Música e Artes Visuais (BRASIL, 1998).

Olh@res, Guarulhos, v. 3, n. 1, p. 143-167. Maio, 2015.
} 
básicos" (BRASIL, 2001, p. 02). Como poderia ser interpretada essa recomendação, no que toca ao ensino de arte? Qual seria o "significado prático e instrumental" da arte? Penso que, a partir dessa recomendação, não se apresentaria um futuro muito promissor para o ensino de arte na educação daqueles com necessidades especiais. Dependendo das concepções sobre arte que tenham os profissionais que trabalham na escola - e, como tentei mostrar, muitas vezes essas concepções são bastante equivocadas - pode ser que a arte perca definitivamente sua importância na Educação Especial, ficando relegada - de maneira ainda mais contundente - aos usos limitadores e empobrecedores elencados acima. Não tendo um "significado prático e instrumental" - e creio que a conotação aqui é a inserção do indivíduo no mercado de trabalho $^{11}$-, à arte caberia, então, a função de auxiliar em outras aprendizagens ou de entreter ou de extravasar emoções. Em nenhum desses casos se pode vislumbrar a sua contribuição efetiva no desenvolvimento das crianças e jovens com necessidades educativas especiais, como não se vislumbra a sua contribuição no desenvolvimento de crianças e jovens sem necessidades especiais. Os postulados de Vigotski e Lukács sobre estética contrastam violentamente com a ideia de transmitir àqueles com necessidades educativas especiais apenas conteúdos com "significado prático e instrumental", no campo da arte ou em qualquer outro.

É urgente superar, no ensino de arte, fazeres tão pouco significativos como os que apontei anteriormente.Baseando-me nos autores aqui chamados, é possível afirmar que o ensino de arte na escola regular, destinado às crianças com ou sem necessidades educativas especiais, deveria ter como objetivos principais: 1.a apropriação das mais altas conquistas humanas no campo da arte; 2. o desenvolvimento da criação e da imaginação; e 3. a ampliação da consciência através da catarse. Somente se perseguir esses objetivos a arte (e seu ensino)poderá ocupar um lugar importante na formação omnilateralde todos os indivíduos.Evidentemente, isso exige a formulação

\footnotetext{
${ }^{11}$ É possível que alguém veja nessa recomendação a possibilidade de o indivíduo com necessidades educativas especiais se valer do trabalho com a arte para a sua sobrevivência. Mas convenhamos que esse é um mercado bastante restrito e incerto. Ademais, não é essa a função única e precípua da arte na formação humana, como se viu com Vigotski e Lukács.

Olh@res, Guarulhos, v. 3, n. 1, p. 143-167. Maio, 2015.
} 
de metodologias adequadas, bastante diversas dos espontaneísmos reinantes nas aulas de arte ${ }^{12}$.

\section{Ainda algumas palavras}

A essa altura, pode estar parecendo que considero pouco ou menos importante a luta pela inclusão escolar das crianças e jovens com necessidades especiais; essa seria, contudo, uma interpretação equivocada do que foi exposto. Apenas desejei enfatizar a importância de inserir essa luta no âmbito maior da luta pelo direito de todos à educação, porque considero esse um interesse humano universal. Pode parecer também que considero que nada há a se fazer pelos excluídos,enquanto não ocorrer uma profunda transformação social; o que também não é verdade. Penso que conhecer um problema em seus múltiplos determinantes, longe de imobilizar, amplia as possibilidades de superá-lo; assim, os educadores que se sabem constrangidos pela lógica de mercado em sua prática profissional, ao invés de se render a ela, podem, devem, precisam trabalhar nas brechas que as contradições do modo de produção capitalista põem a descoberto, em favor de uma sociedade mais justa e igualitária. Penso que abraçar de modo acrítico e servil a concepção da orientação inclusiva na educação - ou outra qualquer - pode ser totalmente inócuo e deletério; compreender suas origens, seus fundamentos, seus objetivos pode contribuir para a transformação que desejamos.A arte e seu ensino, nesse contexto, ocupam lugar de destaque: ajudam a conhecer a realidade humana, de ontem e de hoje; e ajudam a nos compreendermos, nessa realidade.

\footnotetext{
${ }^{12}$ Nesse sentido, tenho trabalhado em algumas proposições que serão publicadas em breve. Olh@res, Guarulhos, v. 3, n. 1, p. 143-167. Maio, 2015.
} 


\section{Referências bibliográfica}

BARROCO, S. M. S.; LEONARDO, N. S. T.; SILVA, T. dos S. A. da (orgs.). Educação especial e teoria histórico-cultural: em defesa da humanização do homem. Maringá: EDUEM, 2012.

BRASIL.Resolução CNE/CEB n. 2/2001. Brasília, 2001. [Disponível em: http://portal.mec.gov.br/cne/arquivos/pdf/CEB0201.pdf]. Acesso em: 20/12/2014.

DUARTE, N. Arte e formação humana em Vigotski e Lukács. In: ; DELLA FONTE,

S. S. Arte, conhecimento e paixão na formação humana: sete ensaios de pedagogia histórico-crítica. Campinas: Autores Associados, 2010. p. 145-163.

ESPANHA. Declaração de Salamanca e Enquadramento da Acçãona área das necessidades educativas especiais. Salamanca, 1994. [Disponível em:

http://portal.mec.gov.br/seesp/arquivos/pdf/salamanca.pdf]. Acesso em: 20/12/2014.

FERREIRA, N. B. de P. Catarse e literatura: uma análise com base na pedagogia históricocrítica. In: MARSIGLIA, A. C. G. (org.). Infância e pedagogia histórico-crítica. Campinas: Autores Associados, 2013. p. 197-212.

GENTILI, P. O direito à educação e as dinâmicas de exclusão na América Latina. Educação \& Sociedade, Campinas, vol. 30, n. 109, 1059-1079, set./dez. 2009.

KLEIN, L. R.; SILVA, G. L. R. da. Quando o discurso da diferença desdenha a desigualdade: as armadilhas da inclusão. In: BARROCO, S. M. S.; LEONARDO, N. S. T.; SILVA, T. dos S. A. da (orgs.). Educação especial e teoria histórico-cultural: em defesa da humanização do homem. Maringá: EDUEM, 2012.p. 23-39.

KONDER, L. O que é dialética. 9ª ed. São Paulo: Brasiliense, 1984.

Estética e política cultural. In: ANTUNES, R.; RÊGO, W. L. Lukács: um Galileu no século XX. $2^{\mathrm{a}}$ ed. São Paulo: Boitempo, 1996.p. 27-33.

LEONTIEV, A. O desenvolvimento do psiquismo. Lisboa: Livros Horizonte, 1978.

MARTINS, L. M. O desenvolvimento do psiquismo e a educação escolar: contribuições à luz da psicologia histórico-cultural e da pedagogia histórico-crítica. Campinas: Autores Associados, 2013.

MARX, K. Manuscritos econômicos e filosóficos. São Paulo: Paz e Terra, 1974 (Abril Cultural: Coleção Os Pensadores).p. 09-54.

OLIVEIRA, A. da R. Marx e a exclusão. Bajé: Seiva, 2004.

PADILHA, A. M. L.; BARBOSA, M. F. S. A exclusão em foco: modos de olhar. In: SILVA, L. B. de O.; BARCELLOS, A. C. K.; PADILHA, A. M. L. (orgs.). O diálogo em educação: um caminho ou uma nova paideia para uma reflexão sobre a educação numa sociedade de consumidores. São Carlos: Pedro \& João Editores, 2013. p. 143-157.

PADILHA, A. M. L.; OLIVEIRA, I. M. de (orgs.). Educação para todos: as muitas faces da inclusão. Campinas: Papirus, 2013. 
SADER, E. Século XX: uma biografia não autorizada - o século do imperialismo. São Paulo: Fundação Perseu Abramo, 2001.

SAVIANI, D. Escola e democracia: teorias da educação, curvatura da vara, onze teses sobre a educação política. $35^{\mathrm{a}}$ ed. revista. Campinas: Autores Associados, 2002.

Prefácio. In:BARROCO, S. M. S.; LEONARDO, N. S. T.; SILVA, T. dos S. A. da (orgs.). Educação especial e teoria histórico-cultural: em defesa da humanização do homem. Maringá: EDUEM, 2012.p. 07-10.

VIGOTSKI, L. S. Obras Escogidas. Tomo V. Madri: Visor, 1997.

Psicologia da Arte. São Paulo: Martins Fontes, 1998.

. A educação estética. In: Psicologia pedagógica. São Paulo: Martins Fontes, 2004.p. 321-363.

Imaginação e criação na infância: ensaio psicológico - livro para professores. São Paulo: Ática, 2009.

Recebio para publicação em 31 de janeiro de 2015

Aprovado em 08 de abril de 2015 